\title{
Uma Reflexão sobre o Material Didático de um Curso de Graduação a Distância do Ponto de Vista de seus Tutores
}

Cledja Mônica Gomes de França Reis, Instituto de Computação/UFAL, cmgfr@hotmail.com

Vânia Cristina S. de Sampaio, Instituto de Computação/UFAL, vaniasampaio82@yahoo.com.br Olival de Gusmão Freitas Júnior, Instituto de Computação/UFAL, olival@ic.ufal.br Arturo Hernández-Domínguez, Instituto de Computação/UFAL, arturohd@ic.ufal.br

Resumo: Este artigo apresenta uma análise do material didático produzido para um curso de graduação a distância em uma Instituição Federal de Ensino Superior brasileira sob a ótica dos seus tutores. Verifica-se que o tutor é o elo na mediação do processo de ensino e aprendizagem entre aluno, conteúdos, professor e demais elementos que integram o processo de Educação a Distância (EaD). Os dados dessa pesquisa foram coletados a partir da aplicação de um questionário com os tutores do curso de Bacharelado em Sistemas de Informação (BSI) da Universidade Federal de Alagoas (UFAL), observando a sua relevância no processo de ensino aprendizagem. Nos resultados obtidos, observou-se que os tutores não participam efetivamente na elaboração do plano de tutoria e o material didático ofertado pelo referido curso foi avaliado positivamente pelos seus tutores.

Palavras-chave: Educação a Distância, Material didático, Tutor.

\section{A Reflection on the Teaching Material of an Undergraduate Course Distance taking into account Point of View of their Tutors}

\begin{abstract}
This paper presents an analysis of educational materials produced for an undergraduate degree at a distance in a Federal Institution of Brazilian Higher Education from the perspective of their tutors. The tutor is the link in mediating the teaching and learning process between student, content, teacher and other elements that are part of the process of Distance Education (DE). The data from this study were collected from the application of a questionnaire with the tutors of the course of Bachelor of Information Systems (BIS) of the Federal University of Alagoas, noting its relevance in the teaching learning process. The results, it was observed that the tutors do not participate effectively in developing the mentoring plan and teaching material offered by that course was evaluated positively by their tutors..
\end{abstract}

Keywords: Distance education, Educational Material, Tutor.

\section{Introdução}

$\mathrm{O}$ atual processo de mudança nas atividades econômicas dos países, causados pela globalização, pelo aumento da concorrência, pelos avanços na tecnologia da informação e comunicação vem exigindo das pessoas um permanente aperfeiçoamento e uma formação especializada para atuar no mercado produtivo.

A característica essencial da Educação a Distância $(\mathrm{EaD})$ é o envolvimento do aluno nas atividades de aprendizagem em um local onde o professor não está fisicamente presente, tendo maior flexibilidade para gerenciar seu tempo e desenvolver suas atividades acadêmicas. Na 
EaD, a distância física é superada pelo uso das Tecnologias de Informação e Comunicação que conectam professores, alunos e tutores fisicamente distantes (Carvalho, 2007).

Nesse contexto, convém destacar um elemento de extrema relevância nesse processo de ensino, o tutor. Ele é um sujeito indispensável, e de atuação imprescindível na $\mathrm{EaD}$, podendo atuar tanto na modalidade à distância, como na presencial, exercendo a função de apoio pedagógico. O tutor é o elo na mediação do processo de ensino e aprendizagem entre aluno, conteúdos, professor e demais elementos que integram o processo. Seu trabalho é desenvolvido em parceria com o docente, auxiliando-o neste acompanhamento.

O objetivo dessa pesquisa é apresentar uma análise do material didático produzido para um curso de graduação a distância em uma Instituição Federal de Ensino Superior brasileira sob a visão dos seus tutores.

\section{Referencial teórico}

\subsection{A produção de material didático em EaD}

Segundo Belisário (2003, p. 136), entre os diversos pontos importantes que se identificam no desenvolvimento de programas de $\mathrm{EaD}$, está à produção do material didático. Nesse sentido, afirma Fleming (2004, p. 23) que:

"O material didático para EaD configura-se como um conjunto de mídias (impresso, audiovisual e informáticos), no qual os conteúdos apresentam-se de forma dialógica e contextualizada, favorecendo uma aprendizagem significativa. O projeto político-pedagógico dos cursos, dentre outros aspectos, deve orientar as escolhas quanto aos recursos didáticos necessários para o alcance dos objetivos educacionais propostos. Quanto mais diversificado o material, mais nos aproximamos das diferentes realidades dos educandos e possibilitamos diferentes formas de interagir com o conteúdo."

Em $\mathrm{EaD}$, o material didático é um elemento mediador que traz em seu cerne a concepção pedagógica que norteia o ensino aprendizagem e, sendo assim, o planejamento e constituição do material didático que irá mediar situações de ensino aprendizagem se relaciona com a concepção pedagógica do produtor deste material (Sales, 2005). Nesse contexto, concorda-se com a visão ofertada por Santos et al. (2006, p. 2), quando se expressa dizendo que:

"As perspectivas atuais de uso das mídias na $\mathrm{EaD}$, com alternativas de comunicação e maneiras de utilização em contínuo desenvolvimento, exigem uma permanente atualização e flexibilidade para analisar as possibilidades de incorporar esses meios nas atividades docente/discente na EaD."

Nesse sentido, pode ser compreendido que entre os diversos fatores a serem considerados na seleção da mídia, merecem destaque três fatores: o acesso dos alunos, a aplicabilidade e o custo. É salutar o entendimento de que a mediação da relação aluno/educador e o processo de aprendizagem na EaD passa pela interação com as mídias disponíveis, e esta, como bem explica Santos et al. (2006, p. 2) deve ser vista e entendida na perspectiva da tecnologia educacional, como um meio e não como um fim.

Os modelos de material didático no contexto atual de EaD se voltam para a utilização de mídias digitais, porém, o material impresso ainda é uma mídia bastante utilizada e, por que não dizer a de maior custo-benefício nos cursos dessa modalidade de educação. Por esse motivo é que muitos autores destacam nos seus estudos a importância desse tipo de mídia na EaD.

No entanto, é interessante entender que falar de material didático é referir-se a uma diversidade de meios tecnológicos que podem ser utilizados no ato de ensinar, 
tendo como objetivo a aprendizagem por parte do aluno. Nesse sentido, explica Palange (2009, p. 382) que:

"Os materiais didáticos e os recursos educacionais na $\mathrm{EaD}$ em ambientes virtuais de aprendizagem são destacados como meios para o desenvolvimento do conteúdo, dentre esses recursos ela apresenta: textos, vídeos, animações, jogos e outros sempre questionando se estimulam o diálogo com o aluno."

$\mathrm{Na}$ produção do material didático alguns aspectos são de fundamental importância, a exemplo dos aspectos técnicos e pedagógicos, que na visão de Fernandez (2009, p. 399) precisam ser considerados e respeitados. Esses aspectos são apresentados pelo autor como sendo: o perfil do aluno; a qualidade da linguagem; a relevância do conteúdo; o caráter de parceria entre especialistas e adequação na inserção dos elementos formais e o respeito à autoria.

A concepção do material didático deve estar "de acordo com os princípios epistemológicos, metodológico e político, explicitados no projeto pedagógico". Esse pensamento é reforçado em Mercado (2007, p. 27), quando diz que "o material didático sempre esteve presente em qualquer processo de ensino aprendizagem, devendo seguir critérios para seu uso, levando em consideração que é desenvolvido para o aluno e não para a tecnologia".

E nesse contexto, fazer uma avaliação do uso dos materiais didáticos nos ambientes virtuais é indiscutivelmente uma forma de avaliar como os conteúdos estão chegando aos alunos (Palange, 2009). Para tanto, se faz necessário o reconhecimento do resultado da avaliação, bem como estar preparado para as críticas, buscando-se com isso o aprimoramento. Segundo Fernandez (2009, p. 20):

"Cada material didático tem suas características e fins, sendo também a mediação entre o aluno e a aprendizagem, por esse motivo, avaliar o uso desses materiais didáticos é uma ação importante para se obter um resultado satisfatório da aprendizagem na EaD."

Sales (2005, p. 3) destaca também que o material didático da EaD deve objetivar a busca de um instrumento de aprendizagem que apresente as seguintes condições: interatividade; sequência de idéias e conteúdos; relação teoria e prática; auto-avaliação; linguagem clara e concisa; glossário; exemplificações cotidianas e/ou científicas e resumos e animações.

\subsection{O papel do tutor na EaD}

O profissional que assume a função de tutor é o individuo responsável pelo acompanhamento do processo de ensino aprendizagem. Ele deve ter uma postura diferenciada do modelo tradicional de docente, haja vista que o seu objetivo é orientar o aluno nesse processo, com isso, ocorre uma interação entre ambos. Outro aspecto importante diz respeito a possuir formação condizente com a disciplina a ser ofertada pelo curso. Sob essa ótica, o tutor é tido como o orientador do aluno em $\mathrm{EaD}$ e exerce como principal função a de acompanhar a vida acadêmica dos alunos, apontando caminhos e encontrando, em parceria, soluções para determinados problemas ou propostas (Schlosser, 2010).

Segundo Nunes (2013, p.3), o tutor deve ser compreendido como um dos atores que participam ativamente da prática pedagógica. Suas atividades desenvolvidas devem contribuir para o desenvolvimento dos processos de ensino aprendizagem e para o acompanhamento e avaliação do projeto pedagógico. Vale ressaltar que o tutor seleciona, na medida em que detecta as deficiências, as melhores soluções, para que desta forma, possa motivar o aluno na aquisição do seu próprio conhecimento. 
Em relação ao exercício da tutoria, o tutor tem como compromisso conhecer os conteúdos do curso, ter plena ciência das suas atividades, atribuições, conhecimento do material didático utilizado, regras, assim como do plano de tutoria

Outra característica que a Instituição Federal de Ensino Superior segue diz respeito aos tipos de tutor, sendo um presencial e outro a distancia. O primeiro fica lotado no pólo e seu papel é sanar eventuais dúvidas dos alunos que surgem ao longo do curso, já o segundo desenvolve suas atividades no ambiente virtual de aprendizagem.

O tutor é acompanhado pela coordenação de tutoria, para a melhor qualidade dos serviços prestados por esses indivíduos no processo de ensino aprendizagem, havendo momentos de orientação da sua pratica, em encontros de capacitação no intuito de que o mesmo obtenha êxito na execução das suas atribuições enquanto tutor, e avaliação permanente de suas atividades, sistematizada pelos órgãos de gerenciamento, responsáveis, tais como: coordenação do curso, coordenação de tutoria e pela coordenação de educação a distância.

\section{Procedimentos metodológicos}

A pesquisa realizada nesse estudo utilizou métodos quantitativos para elencar e analisar a qualidade do material didático e suas implicações no cotidiano dos tutores, bem como no processo de ensino aprendizagem das disciplinas do curso de bacharelado em Sistemas de Informação à distância da Universidade Federal de Alagoas, na modalidade de Educação a Distância.

A pesquisa de campo envolveu a coleta de dados a partir de questionários aplicados com os tutores do referido curso. As perguntas dos questionários visavam conhecer a qualidade do material didático e sua prática. Os questionários foram respondidos por $65 \%$ dos tutores on-line do curso. Os dados foram tabulados e os resultados foram obtidos por meio da aplicação dos conceitos básicos de estatística descritiva e posteriormente apresentados sob a forma de gráficos, objetivando apresentar o fenômeno estudado.

\section{A UFAL e o curso de Sistemas de Informação}

A Universidade Federal de Alagoas (UFAL), vinculada ao Ministério da Educação, é uma instituição pública de educação superior. Cumprindo hoje muitos papéis institucionais que têm se multiplicado à medida que a Instituição cresce em paralelo com o crescimento do próprio Estado, o grande desafio da UFAL é fazer com que o seu crescimento reflita cada vez mais a interação de suas atividades e de sua produção científica às difíceis realidades do estado de Alagoas.

Para a UFAL, esse desafio constitui-se na capacidade de formar profissionais qualificados, realização de pesquisas de interesse social e na concretização das ações de extensão que contribuam para o desenvolvimento regional.

A UFAL começou a ofertar cursos EaD desde a década de 1990 com o curso de pedagogia a distância com o objetivo de capacitar os profissionais da rede básica de ensino do estado de Alagoas. Somente a partir de 2005 a UFAL ingressa no Sistema Universidade Aberta do Brasil (UAB), expandindo a oferta de cursos nesta modalidade.

Em 2007, o Instituto de Computação da UFAL oferta a primeira turma do Curso de Graduação de Bacharelado em Sistemas de Informação (BSI), modalidade a distância, com 200 (duzentas) vagas distribuídos em quatro pólos de apoio presencial: Maceió, Maragogi, Santana do Ipanema e Olho D’Água das Flores. Em 2009, foi ofertada a sua segunda turma, mantendo as 200 vagas. Em 2010 teve início a sua terceira turma também ofertando 200 vagas nos quatro pólos iniciais. Ou seja, todos os anos são ofertados 200 vagas para o curso de BSI. 
O Curso de BSI da UFAL foi avaliado em 2012 pelo MEC com o conceito 4. Contudo, existe uma série de problemas inerentes ao curso que estão sendo aprimorados pelo seu colegiado, tais como: a reforma do seu PPC, melhorar a qualidade do material didático das disciplinas e a capacitação de docentes e tutores para atuarem nesta modalidade de EaD.

\section{Resultados}

Como instrumento de pesquisa utilizado foi aplicado um questionário aos tutores. A estrutura das perguntas do questionário avalia os seguintes aspectos: participação do tutor na elaboração do plano de tutoria da disciplina, encontros presenciais com o docente, clareza das orientações, grau de dificuldades nas atividades e dos conteúdos, relação na articulação entre conteúdos e carga horária, a interação entre docente/tutor/turma, critérios de avaliação das atividades, infraestrutura da EaD e avaliação do material didático.

Para as análises das respostas, foram respeitadas as opiniões dos tutores de acordo como a estrutura do questionário que serviu para avaliar o nível de satisfação dos tutores em relação ao material didático.

A primeira questão do questionário aborda a participação dos tutores na elaboração do plano de tutoria. A atividade de tutoria, no âmbito da $\mathrm{EaD}$, diz respeito ao acompanhamento e a orientação sistemática dos alunos por profissionais experientes na área de formação. O plano de tutoria é um documento elaborado pelo docente que detalha todas as atividades, ações e avaliações a serem realizadas em uma disciplina e quem será o responsável por elas (docente ou tutor). Ou seja, o plano serve de guia para o tutor no desenvolvimento do seu trabalho de tutoria junto ao docente na disciplina. Esse documento deve ser elaborado conjuntamente com os tutores e deve constar: ementa da disciplina, objetivos da disciplina, metodologia adotada, avaliações e atividades (detalhando a pontuação), prazo limites para entrega das atividades, bibliografia adotada e recomendada.

O Gráfico1 mostra que 61,53\% dos tutores do curso de sistemas de informação da UFAL afirmaram que é insuficiente a participação dos tutores na elaboração dos planos de tutoria das disciplinas do curso de BSI da UFAL. Todavia, 23,07\% afirmaram ser boa essa elaboração, ou seja, participa do seu processo de discussão e elaboração. Já $7,69 \%$ afirmaram ser muito boa essa participação e os outros 7,69\% afirmaram ser suficiente. A sugestão é que antes do começo de cada disciplina haja uma reunião com os tutores e o docente responsável para elaboração conjunta do plano de tutoria. 
Gráfico1 - Questão 1

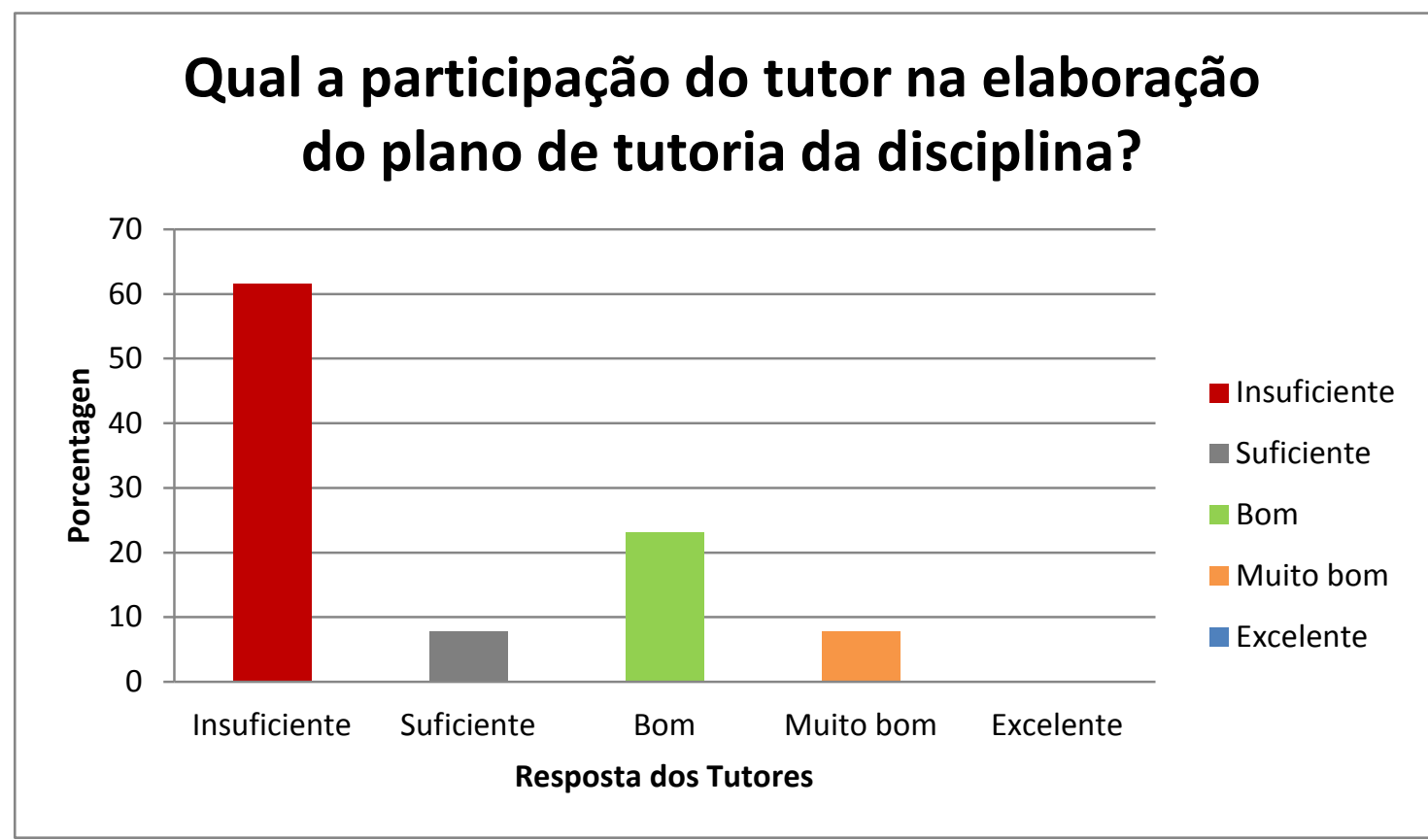

A quarta questão foca a coerência entre o grau de dificuldade das atividades desenvolvidas nas disciplinas e os conteúdos vistos. Pelo Gráfico 2, 46,15\% dos tutores afirmaram ser boa essa coerência entre o grau de dificuldade das atividades e dos conteúdos vistos. Já 30,76\% afirmaram que essa coerência é muito boa e 7,69\% afirmaram ser insuficiente, enquanto 7,69\% afirmaram ser suficiente e os outros 7,69\% excelente. Isso representa um ponto positivo para o curso de BSI, pois mostra a sintonia existente entre atividades e conteúdo programático.

Gráfico 2 - Questão 4

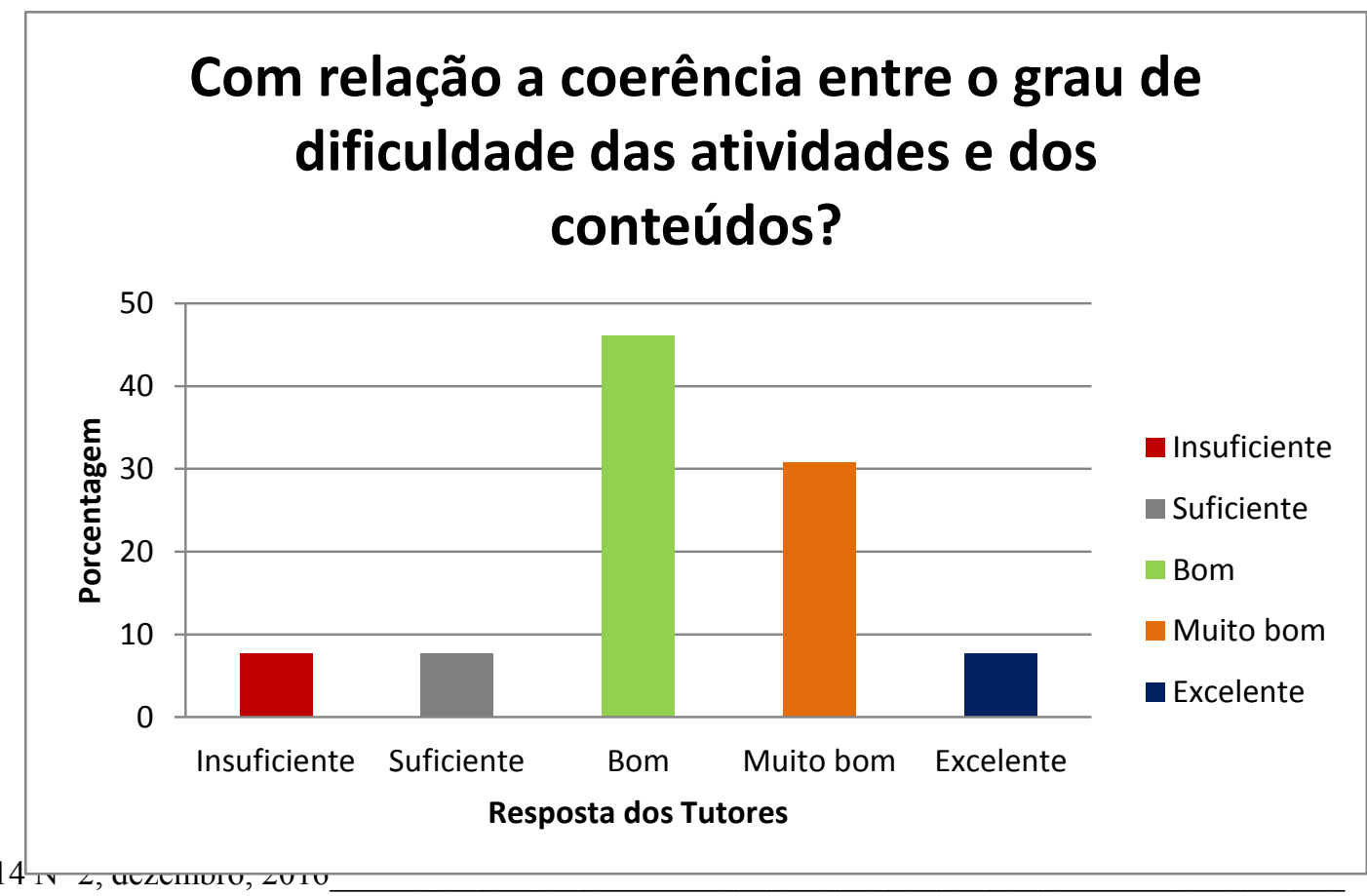

V. 14 IV L, ULZUIIUTU, LVIU 
A sétima questão aborda a interação entre o docente/tutor/turma. Essa interação é fundamental para o sucesso na disciplina e do próprio curso. O Gráfico 3 mostra que $38,46 \%$ dos tutores consideram boas essas interações entre os docentes-tutores-turmas, enquanto $30,76 \%$ consideram muito boa. $15,38 \%$ consideram finalmente insuficiente essa relação e $7,69 \%$ consideram suficiente e outros $7,69 \%$ excelente.

Gráfico 3 - Questão 7

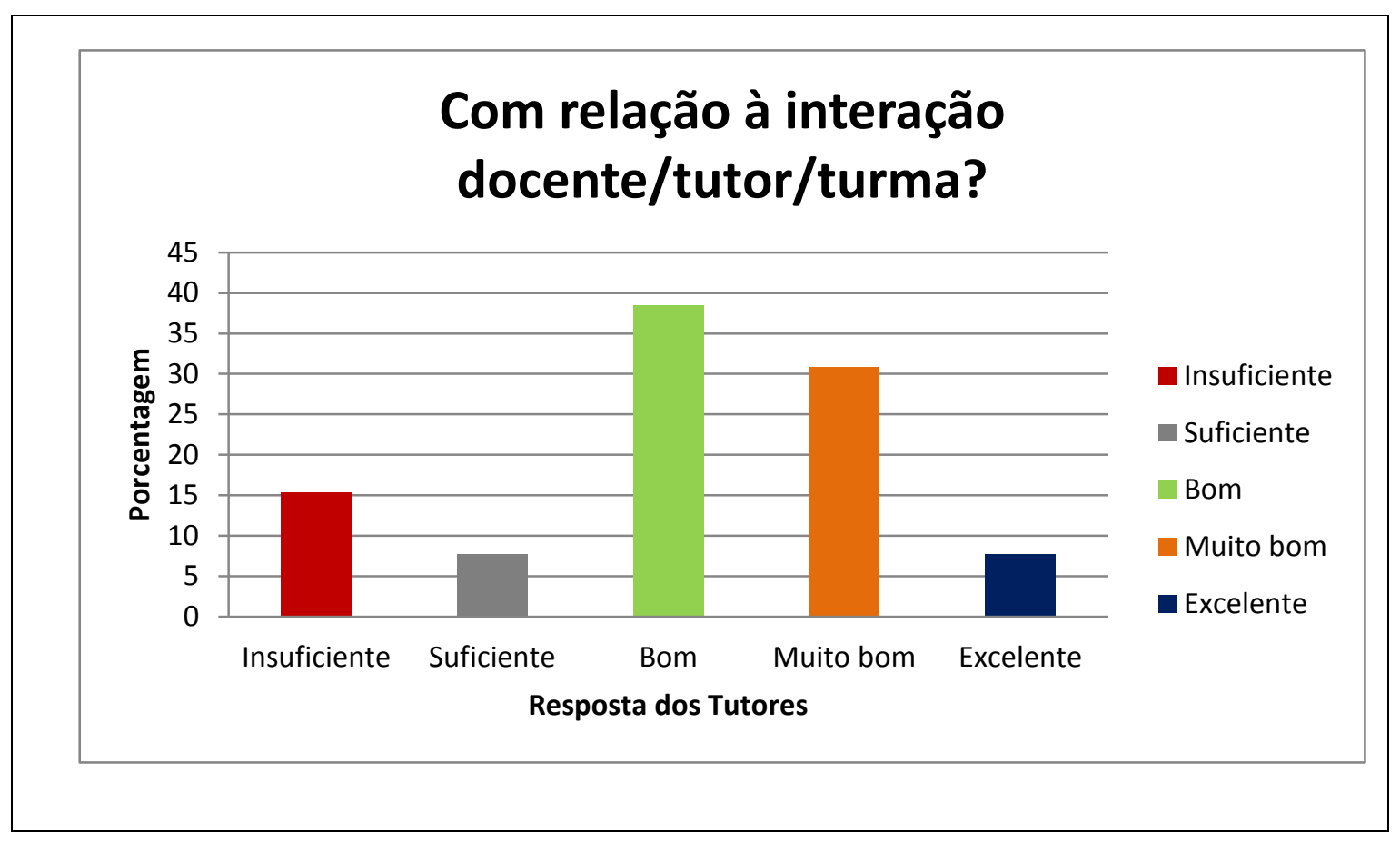

A décima questão especifica a nota que os tutores dariam para os materiais didáticos utilizados nas disciplinas do curso. No Gráfico 4, observa-se que os tutores avaliaram com a média 6,84 os materiais didáticos do curso de BSI da UFAL. 


\section{Gráfico 4 - Questão 10}

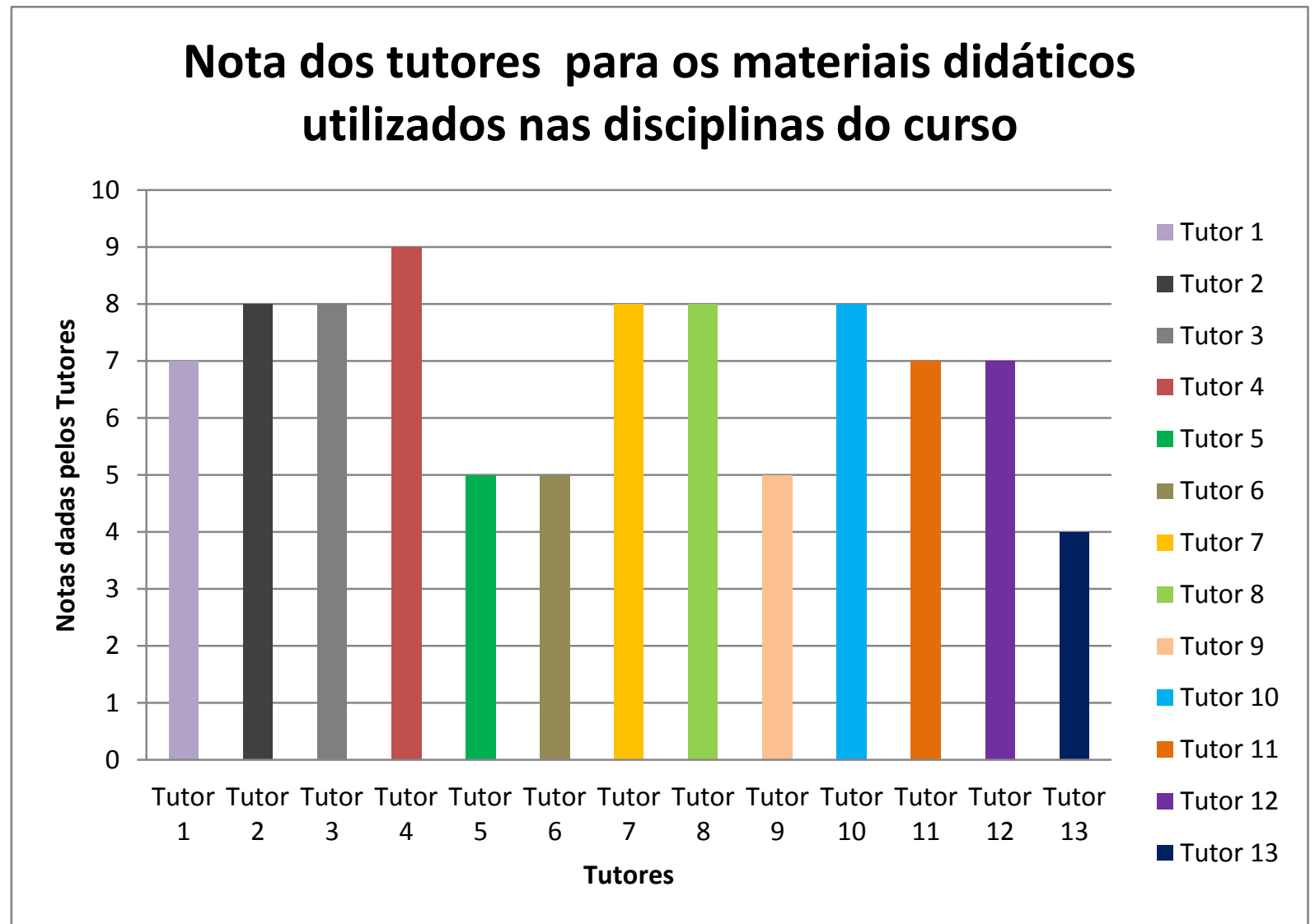

$\mathrm{Na}$ última questão foi perguntado como o docente poderia melhorar o material didático do curso? Cada tutor se manifestou de uma forma diferente:

Tutor 1: O material didático deve ser ilustrativo e com diversos exercícios.

Tutor 2: O material didático deve abordar os assuntos de forma mais prática e menos teórica, usando ferramentas que possam ajudar o aluno a construir seu próprio conhecimento (p.e., mapas conceituais).

Tutor 3: Os docentes devem adotar práticas de utilização de vídeo-aula para que o aluno não perca o foco do que deve ser aprendido.

Tutor 4: Da mesma forma, o docente deve adotar vídeo-aula. No plano de ensino, o docente deve deixar claro quais são as atividades da semana.

Tutor 5: O docente deve deixar claro quais são os objetivos de aprendizagem de cada semana da disciplina. A partir disso, cada docente pode desenvolver o seu material didático voltado para a obtenção das competências da disciplina alinhado com o perfil do egresso do aluno que consta no PPC do curso de BSI.

Tutor 6: Os recursos poderiam ser melhor adaptados para as especificidades didáticopedagógicas da $\mathrm{EaD}$. Com isso, evita-se a transposição de métodos do ensino presencial bem com elaborar materiais que permitam maior interatividade.

Tutor 7: Com a utilização de um material (livros, revistas e artigos acadêmicos) mais 
recente, fazendo uma conexão com os temas e assuntos da disciplina na atualidade.

Tutor 8: Nada a declarar.

Tutor 9: Sendo adequados à realidade do público-alvo, nossos discentes. Avaliações também devem ser realizadas com os formandos do curso de BSI, no sentido de identificar possíveis falhas e traçar melhorias.

Tutor 10: Trazendo exemplos de aplicações de Sistemas de Informação nos mais diversos setores.

Ilustrando mais os conteúdos que são de difícil compreensão.

Trazendo a explicação (fala do professor) dentro do material didático do aluno.

Tutor 11: Acredito que, criando-se uma estrutura padrão para elaboração do material do curso de BSI, este teria uma identidade que seria facilmente observada pelos alunos em todas as disciplinas, e assim os discentes poderiam organizar melhor seus estudos.

Tutor 12: A padronização nas apresentações pode ser vista como um ponto positivo, pois reflete a organização da coordenação. Neste caso, uma equipe seria necessária para criar os padrões (documentos, planilhas, etc.) e validar o material criado pelo docente/tutor. Os recursos multimídia são valiosos nesse contexto, então devemos abusar no uso desse recurso. Os alunos sentem uma grande dificuldade quando não há esse tipo de material disponível. Acredito também, que a participação do tutor na elaboração do material, seja com conteúdo ou sugestões, seria fundamental para obter um melhor aproveitamento.

Tutor 13: Os materiais online devem conter mais vídeos e menos texto, os textos devem ser encontrados em livros que podem ser disponibilizados nas bibliotecas dos pólos, porem o conteúdo semanal geralmente é exposto apenas texto e não vídeo com aula do professor.

Portanto, percebeu-se de acordo com as respostas dos tutores que o material didático ofertado pelo curso de BSI da UFAL, foi avaliado positivamente. Contudo esse curso deve melhorar a qualidade do material didático ofertado e para isto é necessário levar em consideração as respostas dos tutores ao questionário.

\section{Conclusão}

Este trabalho apresenta uma análise do uso do material didático produzido pelo curso de Bacharelado em Sistemas de Informação (BSI) da Universidade Federal de Alagoas (UFAL) sob o ponto de vista dos seus tutores.

Como resultados dessa pesquisa, observado sob o ponto de vista dos tutores, alguns aspectos positivos e negativos relacionados ao material didático, produzido pelos docentes do Curso de BSI da UFAL, precisam ser revistos e/ou aperfeiçoados.

Os tutores sugeriram aspectos que são fundamentais e necessitam ser adotados pelos docentes do Curso de BSI da UFAL, entre eles estão: adotar práticas de utilização de vídeo-aula em todas as disciplinas; utilização de mapas conceituais; material didático mais ilustrativo e com mais exercícios. Esses recursos, aliados ao material impresso, poderiam proporcionar uma melhor qualidade do material didático utilizado no referido curso. 
Ficou perceptível durante este estudo que há uma necessidade de tornar mais claro e objetivo o material didático. Bem como haver uma participação maior do tutor quanto a sugestões (sobre problemas em relação ao andamento da disciplina) que os mesmos identificam durante os momentos presenciais, onde eles têm contato direto com os alunos. Também no ambiente virtual as dificuldades são apresentadas pelos alunos através das interações on-line, podendo ser detectados possíveis soluções a problemas que atrapalham a interação dos alunos.

A pesquisa demonstrou (através da avaliação dos tutores) como positiva a produção do material didático confeccionado (pelos docentes) para o curso de Bacharelado em Sistemas de Informação da UFAL.

Os resultados desta pesquisa serão comunicados ao coordenador atual do curso de BSI da UFAL.

\section{Referências}

BELISÁRIO, A. (2003).O material didático na educação a distância e a constituição de propostas interativas. In: SILVA, Marco (org). Educação online. São Paulo: Loyola.

CARVAlHO, A. B. (2007). Os Múltiplos Papéis do Professor em Educação a Distância: Uma Abordagem Centrada na Aprendizagem In: Anais do $1^{\circ}$ Encontro de Pesquisa Educacional do Norte e Nordeste, Maceió.

FERNANDEZ, C. T. (2009). Os métodos de preparação de material impresso para EaD. In: LITTO, F. M.; FORMIGA, M. M. M (Orgs.). Educação à distância: o estado da arte. São Paulo: Pearson Education no Brasil.

FLEMING, D. M. (2013) Desenvolvimento de Material Didático para Educação a Distância no contexto da Educação Matemática. São Paulo, 2004. Disponível em: www.abed.org.br. Acesso em: 18/fev/2013.

MERCADO, L. P. L. (2007). Percursos na formação de professores com tecnologias da informação e comunicação na educação. Maceió: Edufal.

NUNES, V. B. (2013). O Papel do Tutor na Educação a Distância: Como tem sido concebido pelas instituições de ensino? Disponível em: http://www.abed.org.br/congresso2013/cd/41.pdf. Acesso em: 01/mar/2013.

PALANGE, I. (2009). Os métodos de preparação para cursos on-line. In: LITTO, F. M.; FORMIGA, M. M. M (Orgs.). Educação à distância: o estado da arte. São Paulo: Pearson education no Brasil.

SALES, M. V. S. (2005). Uma reflexão sobre a produção do material didático para EaD. Disponível em: http://www.abed.org.br/congresso2005/por/pdf/044tcf5.pdf. Acesso em: 01/mar/2013.

SANTOS, C. R.; ZANETTE, E. N.; NICOLEIT, G. F. G.; FIUZA, P. J. (2006). A Construção do Material Didático para a Educação a Distância: a experiência do setor de educação a distância da UNESC. Disponível em:http://pt.calameo.com/read/000103547cfb4abbda14f. Acesso em: 01/mar/2013.

SCHLOSSER, R. L. (2010). A Atuação dos Tutores nos Cursos de Educação a Distância. http://pead.ucpel.tche.br/revistas/índex.php/colabora/article/view/128/112. Acesso em: 01/mar/2013. 